\title{
Trabalho intensificado e afastamento do trabalho: uma análise nos frigoríficos no estado de Mato Grosso do Sul
}

\author{
Gustavo Henrique Petean ${ }^{1}$ \\ ELCIO GUSTAVO BENINI ${ }^{2}$ \\ Gabriel Gualhanone Nemirovsky ${ }^{3}$

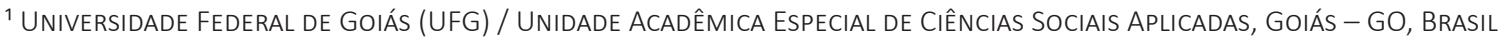 \\ 2 Universidade Federal de Mato Grosso do Sul (UFMS) / Escola de AdMinistraçÃo e Negócios, Campo Grande - MS, BRASIL \\ 3 Universidade Federal de Mato Grosso do Sul (UFMS) / CAMpus Nova ANDRAdINA, Nova ANdRAdINA - MS, BRASIL
}

\begin{abstract}
Resumo
Os abatedouros de bovinos, suínos e aves estão entre as dez atividades econômicas que mais empregam no estado de Mato Grosso do Sul. Contudo, figuram entre aquelas com maiores índices de afastamento do trabalho por acidentes ou doença. Diante disso, o objetivo deste artigo é analisar a relação de intensificação e dos afastamentos do trabalho nos frigoríficos do estado. À luz do materialismo histórico, a pesquisa se utilizou das bases de dados da Relação Anual de Informações Sociais (Rais) e do banco de dados do Ministério da Agricultura referente ao abate de carne no estado de Mato Grosso do Sul (Sipoa/DDA/SFA-MS), bem como, de forma complementar, recorreu à análise documental de processos trabalhistas do Tribunal Regional do Trabalho e de procedimentos do Ministério Público do Trabalho. Por meio da triangulação dos dados, foi possível concluir que há relação positiva entre a intensificação do trabalho e os afastamentos nos frigoríficos. Esse processo se materializa na intensificação da exploração do trabalho no período entre 2007 e 2017. Um trabalhador em 2017 produziu o equivalente a 1,75 trabalhador de 2007. Foi constatado que o processo de intensificação do trabalho tem levado os trabalhadores ao adoecimento. Em 2017, foram registrados 1387 afastamentos de longo período, trabalhadores que permaneceram afastados de suas funções laborais por 360 dias ou mais, o equivalente a 5,3\% dos empregados do setor frigorífico.
\end{abstract}

Palavras-chave: Adoecimento no trabalho. Afastamento do trabalho. Frigorífico. Intensificação do trabalho.

\section{Intensified work and absence from work: an analysis in slaughterhouses in the state of Mato Grosso do Sul}

\begin{abstract}
Slaughterhouses are among the ten economic activities that employ the most people in the state of Mato Grosso do Sul. However, they also have have the highest rates of absence from work due to accidents or illness. This article aims to analyze the relationship of intensification and leave from work in slaughterhouses in Mato Grosso do Sul. In the light of historical materialism, this research deployed the databases of the Annual List of Social Information and the database of the Ministry of Agriculture regarding animal slaughter in the state of Mato Grosso do Sul and, in a complementary way, resorted to the documentary analysis of labor lawsuits of the Regional Labor Court and procedures of the Public Ministry of Labor. Through data triangulation, it was possible to conclude there is a positive relationship between the intensification of work and absences in the slaughterhouses. This process is materialized in the intensification of labor exploitation between 2007 to 2017. One worker in 2017 produced the equivalent of 1.75 workers in 2007. The results show that the intensification of work has led workers to illness. In 2017, 1387 long-term absences were recorded, with workers were absent from work for 360 days or more, equivalent to $5.3 \%$ of employees in the slaughterhouse sector.
\end{abstract}

Keywords: IIIness at work. Absence from work. Slaughterhouse. Work intensification.

\section{Trabajo intensificado y licencias laborales: un análisis en mataderos del estado de Mato Grosso do Sul}

\section{Resumen}

Los mataderos de ganado bovino, porcino y avícola se encuentran entre las diez actividades económicas que más emplean en el estado de Mato Grosso do Sul. Sin embargo, figuran entre las actividades que presentan las tasas más altas de ausentismo laboral por accidente o enfermedad. Por lo tanto, el objetivo de este artículo fue analizar la relación de la intensificación y de las licencias del trabajo en los mataderos de Mato Grosso do Sul. A la luz del materialismo histórico, la investigación utilizó las bases de datos de la Lista Anual de Información Social y del Ministerio de Agricultura sobre el sacrificio de ganado en el estado de Mato Grosso do Sul y, de forma complementaria, recurrió al análisis documental de demandas laborales del Tribunal Laboral Regional y los procedimientos del Ministerio Público de Trabajo. A través de la triangulación de datos fue posible concluir que existe una relación positiva entre la intensificación del trabajo y las licencias en los mataderos. Este proceso se materializa en la intensificación de la explotación laboral en el período comprendido entre 2007 y 2017. Un trabajador en 2017 produjo el equivalente a 1,75 trabajadores en 2007. Se constató que el proceso de intensificación del trabajo ha llevado a los trabajadores a la enfermedad. En 2017, se registraron 1387 licencias a largo plazo, trabajadores que permanecieron fuera de su trabajo durante 360 días o más, lo que equivale al 5,3\% de los empleados del sector de mataderos.

Palabras clave: Enfermedad en el trabajo. Licencia laboral. Matadero. Intensificación del trabajo. 


\section{INTRODUÇÃO}

Os estudos organizacionais são um campo teórico em disputa. Paula (2008, p. 51), em análise dos estudos críticos no contexto brasileiro, adotando os critérios de "visão desnaturalizada da administração, desvinculação da performance e a intenção emancipatória" ${ }^{11}$ para a classificação de estudo crítico, avaliou que apenas $6,7 \%$ das publicações nos principais periódicos e eventos da área se enquadravam em tais critérios.

Embora os estudos críticos ocupem uma pequena parcela da produção nacional, Faria (2009) identifica uma produção sistemática e relevante no campo. Entretanto, ainda que pese o fato de que a diversidade e a pluralidade sejam quase sempre benéficas para o enriquecimento de quaisquer áreas ou campo específico de conhecimento, é preciso ter certo cuidado com o sentido de crítica, uma vez que uma parcela significativa da crítica organizacional se constitui como crítica funcionalista, ou seja, de manutenção organizacional ou aperfeiçoamento gerencial. ${ }^{2}$ Ainda para o autor, o principal objetivo da crítica deve ser desvelar os vínculos obscuros e manifestos das relações de poder entre indivíduos e entre organizações, considerando sempre o contexto da reprodução sociometabólica do capital.

Cunha e Ferraz (2015, p. 194), por sua vez, explicitam que a perspectiva crítica é a principal "porta de entrada para as demandas da classe trabalhadora no campo dos estudos organizacionais". É preciso ressaltar tal explanação porque, ao considerar o objeto e os objetivos desta pesquisa, foi com o mesmo fundamento que se dedicaram esforços para estudar a relação entre intensificação e acidentes de trabalhos em frigoríficos. Intencionou-se verificar, nos estudos organizacionais, o adoecimento de parte significativa da classe trabalhadora, a fim de denunciar e revelar relações de poder e de controle, algumas tardias, em face do estágio de desenvolvimento do capitalismo, pois os estudos gerenciais parecem ignorar ou apenas oferecer soluções paliativas a tais ocorrências.

Os setores produtivos agrícolas, em especial o frigorífico, têm tido grande relevância econômica, sobretudo para o estado de Mato Grosso do Sul, lócus desta pesquisa. No quarto trimestre de 2017, foi o segundo estado brasileiro em número de abate bovino, ficando atrás apenas de Mato Grosso. Em abate suíno, foi o sétimo do ranking; em aves, o oitavo, no mesmo período (Instituto Brasileiro de Geografia e Estatística [IBGE], 2019). Uma primeira interpretação, talvez a mais lógica, seria que a crescente produtividade estaria ancorada na maior eficiência produtiva (Zylberstajn, 2013), fundamentada num processo da base sociotécnica do trabalho.

Alguns autores, no entanto, observam que o desempenho econômico positivo e a eficiência produtiva do setor ocorrem simultaneamente ao aumento gradativo do adoecimento da força de trabalho (Lacaz, 2016; Vilela et al., 2018). A eficiência produtiva deveria estar acompanhada da preocupação sobre a saúde e a segurança do trabalhador (Vasconcellos, Pignatti \& Pignati, 2009).

Tendo como propósito, portanto, revelar e denunciar relações de poder e de controle, este artigo expõe uma série de contradições internas no processo de valorização do capital e de produção de mercadorias, aqui exploradas na particularidade das relações engendradas pelo processo de produção em frigoríficos, entendidos como uma caricatura moderna da produção manufatureira - o que se apresentou como uma das contribuições ou dos achados para o campo organizacional -, conforme se discute no decorrer do texto.

Com o uso de estruturas historicamente constituídas e de estratégias de dominação sistematicamente concebidas (Antunes, 2011; Ju, Qin, Xu \& Direnzo, 2016), a efetivação do trabalho subsumido pelo capital (Marx, 2013), no qual o trabalhador aceita condições impostas, muitas vezes sem ao menos questioná-las (Lukács, 2013), tem alcançado organizações e setores distintos da sociedade, numa síntese de novas e velhas formas de controle e subsunção do trabalho. Nesse movimento, o frigorífico, como campo particular de tais desenvolvimentos, mostrou-se um espaço privilegiado de pesquisa.

Diante do exposto, o artigo tem como objetivo analisar a relação de intensificação e dos afastamentos do trabalho nos frigoríficos de Mato Grosso do Sul. À luz do materialismo histórico, a pesquisa recorreu às bases de dados da Relação Anual de Informações Sociais (Rais) e do Ministério da Agricultura, referentes ao abate de carne no estado (Sipoa/DDA/SFA-MS),

\footnotetext{
${ }^{1}$ Critérios emprestados de Davel e Alcadipani (2003).

2 Para Faria (2009), é possível pensar o campo crítico sob quatro grandes áreas: a teoria crítica frankfurtiana, com suas respectivas gerações; a teoria crítica em estudos organizacionais, baseada principalmente no materialismo histórico e no método dialético; o critical management studies, interessados sobretudo no aperfeiçoamento da gestão; e a análise crítica em estudos organizacionais, que englobaria perspectivas críticas não marxistas, como o pós-estruturalismo e a fenomenologia.
} 
por meio das quais se procedeu às análises quantitativas, como técnicas de correlação e regressão linear. De forma complementar, incluiu-se a análise documental de processos trabalhistas e de processos e procedimentos do Ministério Público do Trabalho (MPT), ambos da 24ạ região.

No que diz respeito às dimensões espaço-tempo da pesquisa, o campo empírico foi constituído pelos frigoríficos que têm sistema de inspeção federal no Mato Grosso do Sul, sendo 37 empreendimentos listados em 2018. Dois deles apresentam o cadastro nacional de pessoa jurídica em situação baixada e 35 estão aptos para comercializar seus produtos em âmbito federal ${ }^{3}$ (Ministério da Agricultura, 2018). Já o recorte temporal se deu entre os anos de 2007 e 2017.

Este texto está organizado da seguinte forma: a primeira seção trata da exploração relativa do mais-valor absoluto, iniciando-se a discussão pelo processo de subsunção do trabalho na particularidade dos frigoríficos e demonstrando, por meio dos dados da pesquisa, as práticas organizacionais aplicadas aos trabalhadores, em jornadas de trabalho longas e exaustivas, sem ao menos respeitar as normas trabalhistas vigentes, que exigem espaço intrajornada. Na segunda, aborda-se a relação da intensificação e dos afastamentos do trabalho. Por fim, inserem-se as notas finais e as referências.

\section{A EXPLORAÇÃO RELATIVA DO MAIS-VALOR ABSOLUTO}

A ampliação da jornada de trabalho é parte fundamental da compreensão da intensificação do trabalho. A concepção capitalista de usufruto da força de trabalho se expande e apropria do trabalhador por inteiro, controlando-o, após parcelar suas funções, por vezes neutralizando suas capacidades cognitivas, que são transferidas para a gerência (Braverman, 1977). Trata-se de um processo longo, histórico e estrutural, no qual o trabalhador paulatinamente vai se subsumindo ao capital (Faria \& Meneguetti, 2010).

Marx desenvolve o conceito da subsunção, que pode ser apreendido como: "O trabalhador está subsumido ao capital na medida em que não possui meios de produção e é obrigado a se tornar um trabalhador assalariado" (Romero, 2005, p. 19). O conceito é divido em dois: para Marx (2013), a subsunção formal e a real. Como explica Romero (2005), inicialmente a subsunção se dá na maneira formal e ocorre quando "o capital ainda não se apoderou diretamente do processo de trabalho" (Marx, 2013). O trabalhador ainda tem controle sobre o ritmo de trabalho, porém, com as modificações de base técnica, "o lugar da subsunção formal do trabalho é ocupado por sua subsunção real". O autor continua:

[...] uma simples alusão a formas híbridas, em que o mais-valor não se extrai do produtor por coerção direta e que tampouco apresentam a subordinação formal do produtor ao capital. Nesses casos, o capital ainda não se apoderou diretamente do processo de trabalho. Ao lado dos produtores independentes, que exercem seus trabalhos artesanais ou cultivam a terra de modo tradicional, patriarcal, surge o usurário ou o comerciante, o capital usurário ou comercial, que os suga parasitariamente. O predomínio dessa forma de exploração numa sociedade exclui o modo de produção capitalista, ao mesmo tempo que, como na Baixa Idade Média, pode servir de transição para ele. Por último, como mostra o exemplo do trabalho domiciliar moderno, certas formas híbridas são reproduzidas aqui e ali na retaguarda da grande indústria, mesmo que com uma fisionomia completamente alterada. Se, por um lado, para a produção do mais-valor absoluto basta a subsunção meramente formal do trabalho sob o capital por exemplo, que artesãos que antes trabalhavam para si mesmos ou como oficiais de um mestre de corporação passem a atuar como trabalhadores assalariados sob o controle direto do capitalista -, vimos, por outro, que os métodos para a produção do mais-valor relativo são, ao mesmo tempo, métodos para a produção do mais-valor absoluto. Mais ainda, a extensão desmedida da jornada de trabalho mostra-se como o produto mais genuíno da grande indústria. Em geral, tão logo se apodera de um ramo da produção - e, mais ainda, quando se apodera de todos os ramos decisivos da produção-, o modo de produção especificamente capitalista deixa de ser um simples meio para a produção do mais-valor relativo. Ele se converte, agora, na forma geral, socialmente dominante, do processo de produção. Como método particular para a produção do mais-valor relativo, ele atua: em primeiro lugar,

${ }^{3}$ Conforme disponível pela pesquisa trimestral de abate de animais, em 2017, os frigoríficos com inspeção federal foram responsáveis por $90,47 \%$ dos abates em número de cabeças de gado - no território sul-mato-grossense, enquanto os demais 9,53\% se dividiram entre os abates em sistemas de inspeção estadual e municipal (IBGE, 2019). 
apoderando-se de indústrias que até então estavam subordinadas apenas formalmente ao capital; ou seja, atua em sua propagação; em segundo lugar, na medida em que as mudanças nos métodos de produção revolucionam continuamente as indústrias que já se encontram em sua esfera de ação (Marx, 2013, pp. 578-579).

A subsunção real é descrita por Romero (2005, p. 19):

[...] o conceito de subsunção real designa a relação de dominação e subordinação do trabalho frente ao capital do período industrial. Neste momento, o trabalhador passa por um processo de expropriação do seu saber-fazer e cristalização desse conhecimento em um processo mecânico e objetivo (as máquinas-ferramentas). $O$ trabalhador passa a não mais ter domínio completo sobre o ritmo da produção e principalmente, sobre o modo de se produzir - e isso passa a ser ditado pela maquinaria, a qual subsume realmente o trabalhador. Com isso, o aumento da exploração do trabalho pode se dar igualmente pela intensificação do trabalho.

Dessa forma, o trabalhador subsumido ao capital é incorporado ao processo produtivo e perde - ou lhe é retirada - a capacidade de reflexão e ação nos processos de trabalho. A subsunção do trabalhador tem conexões sobre as formas de extração de mais-valor sobre o trabalho, que, como visto no excerto anterior, para Marx, são duas: o mais-valor absoluto e o mais-valor relativo. $\mathrm{O}$ autor os diferencia da seguinte forma: quando "obtido pelo prolongamento da jornada de trabalho, chamo de mais-valor absoluto; o mais-valor que, ao contrário, deriva da redução do tempo de trabalho necessário e da correspondente alteração na proporção entre as duas partes da jornada de trabalho, chamo de mais-valor relativo" (Marx, 2013, p. 390).

Nos frigoríficos estudados, são diversos os registros que desvelam a prática da extensão da jornada de trabalho como algo comum e corriqueiro. As unidades adotam, de forma combinada, a intensificação do trabalho e o prolongamento das jornadas. Os trabalhadores, subsumidos ao capital, "aceitam" a extensão da carga horária. Constatou-se que algumas empresas incluem, no contrato de trabalho, um acordo de prorrogação do horário de trabalho, como se vê na figura a seguir:

Figura 1

Acordo de prorrogação de horário de trabalho

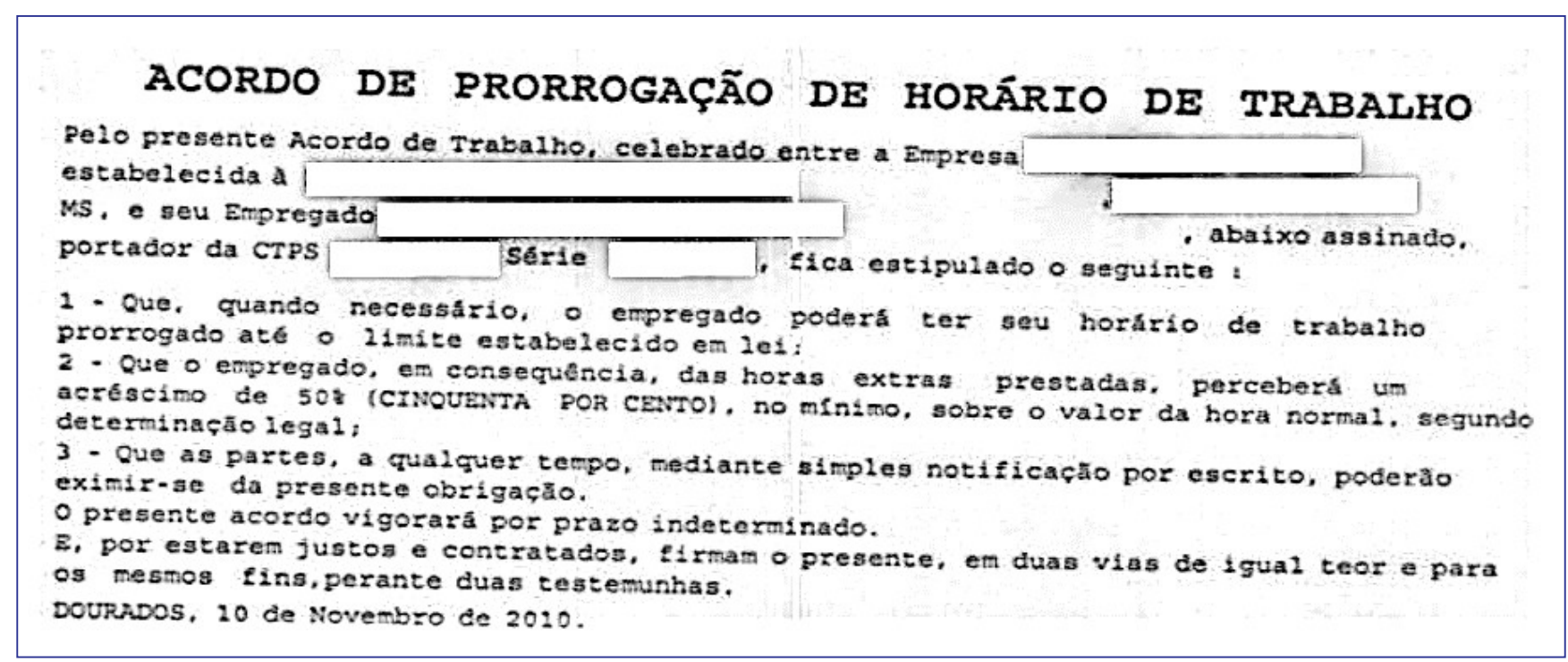

Fonte: Material da pesquisa; processo TRT00X1.

Em outra fonte, verifica-se o registro de ponto de um funcionário durante o período de 20 de maio de 2016 a 19 de junho do mesmo ano. No documento da Figura 2, consta seu horário de trabalho com entrada às 5 h30, intervalo de almoço entre $9 \mathrm{~h} 30$ e $10 \mathrm{~h} 30$ e saída às $14 \mathrm{~h} 30$. No período observado, a carga horária contratada não foi cumprida em nenhum dos dias; sempre houve a incidência de horas extras. Somente no período de 23 a 28 de maio de 2016, foram contabilizadas cinco horas e quinze minutos de hora extra, como mostra a figura a seguir: 
Figura 2

Registro de ponto

\begin{tabular}{|c|c|c|c|c|c|c|c|}
\hline \multicolumn{7}{|c|}{ Periodo $20 / 05 / 2016$ a 19/06/2016 } & \multirow[t]{2}{*}{ Horário 05:30 09:30-10:30 14:30/05:30 09:30 - 8x4 } \\
\hline \multicolumn{7}{|c|}{ Funcionário } & \\
\hline Dia & \multicolumn{4}{|c|}{ Marcaçōes } & \multicolumn{3}{|c|}{ Ocorrências } \\
\hline 20/05/2016 sex-Norm & 05:38 & 09:30 & $10: 30$ & 15:35 & & & \\
\hline 21/05/2016 sáb-Norm & & & & & 04:00 & -533 & COMPENSA DIA \\
\hline 22/05/2016 dom-Folg & & & & & 08:00 & -554 & D.S.R \\
\hline 23/05/2016 seg-Norm & 05:38 & 09:45 & 10:45 & 15:37 & & & \\
\hline 24/05/2016 ter-Norm & 05:35 & 09:45 & 10:45 & 15:30 & & & \\
\hline 25/05/2016 qua-Norm & $05: 34$ & 09:45 & $10: 45$ & $15: 23$ & & & \\
\hline 26/05/2016 qui-Norm & 05:34 & 09:45 & $10: 45$ & 15:28 & & & \\
\hline 27/05/2016 sex-Norm & 05:35 & 09:45 & $10: 45$ & 15:11 & & & \\
\hline 28/05/2016 sáb-Norm & 05:38 & 10:06 & & & & & \\
\hline 29/05/2016 dom-Folg & & & & & 08:00 & -554 & D.S.R \\
\hline 30/05/2016 seg-Norm & 05:35 & 09:30 & $10: 30$ & $15: 29$ & & & \\
\hline 31/05/2016 ter-Norm & 05:34 & 09:30 & 10:30 & 15:00 & & & \\
\hline 01/06/2016 qua-Norm & 05:33 & 09:30 & 10:30 & 15:28 & & & \\
\hline 02/06/2016 qui-Norm & 05:38 & 09:30 & 10:30 & 15:23 & & & \\
\hline 03/06/2016 sex-Norm-Fer & & & & & 08:48 & -538 & FERIADO \\
\hline \multicolumn{8}{|l|}{ 04/06/2016 sáb-Comp } \\
\hline 05/06/2016 dom-Folg & & & & & 08:48 & -554 & D.S.R \\
\hline 06/06/2016 seg-Norm & 05:39 & 09:30 & $10: 30$ & $14: 49$ & & & \\
\hline 07/06/2016 ter-Norm & $05: 40$ & 09:30 & $10: 30$ & 15:08 & & & \\
\hline 08/06/2016 qua-Norm & 05:39 & 09:30 & $10: 30$ & $14: 44$ & & & \\
\hline 09/06/2016 qui-Norm & 05:37 & 09:30 & $10: 30$ & $14: 51$ & & & \\
\hline 10/06/2016 sex-Norm & 05:38 & 09:30 & 10:30 & 14:55 & & & \\
\hline \multicolumn{8}{|l|}{ 11/06/2016 sáb-Comp } \\
\hline 12/06/2016 dom-Folg & & & & & $08: 48$ & -554 & D.S.R \\
\hline 13/06/2016 seg-Norm & 05:38 & 09:30 & $10: 30$ & 15:17 & & & \\
\hline 14/06/2016 ter-Norm & 05:36 & 09:30 & $10: 30$ & $15: 20$ & & & \\
\hline 15/06/2016 qua-Norm & 05:36 & 08:20 & & & & & \\
\hline 16/06/2016 qui-Norm & & & & & $08: 48$ & -506 & ATESTADO MÉDICO \\
\hline 17/06/2016 sex-Norm & & & & & 08:48 & -506 & ATESTADO MÉDICO \\
\hline 18/06/2016 sáb-Comp & & & & & $08: 48$ & -506 & ATESTADO MÉDICO \\
\hline 19/06/2016 dom-Folg & & & & & 08:48 & -554 & D.S.R \\
\hline \multicolumn{8}{|c|}{ Este cartão retrata o ocorrido no periodo } \\
\hline & & & & & Visto da & Chefia & Assinatura do Funcionário \\
\hline
\end{tabular}

Fonte: Material da pesquisa; processo TRT00X2.

A comprovação do uso exacerbado do prolongamento da jornada de trabalho se torna viável no espelho de ponto de um dia de trabalho num frigorífico. O material da pesquisa foi condensado por setor da indústria, conforme consta no relatório completo. $O$ espelho de ponto de 17 de fevereiro de 2014 clarifica a quantidade de horas extras realizadas em cada um desses setores, como visto no Quadro 1. O documento inclui a quantidade de trabalhadores de cada um dos setores e o número de faltantes, independentemente do motivo da ausência, com ou sem atestado. Acrescenta-se que constam faltas no setor de portaria, porém os trabalhadores têm cargas de trabalho diferenciadas, em jornadas de 12 horas de trabalho e 36 de descanso. $O$ espelho do ponto foi resumido no quadro a seguir. 
Quadro 1

Espelho de ponto por setor de um frigorífico em Mato Grosso do Sul no dia 17 de fevereiro de 2014

\begin{tabular}{|c|c|c|c|}
\hline Setor & $\begin{array}{l}\text { Número de } \\
\text { funcionários }\end{array}$ & $\begin{array}{l}\text { Funcionários faltantes } \\
\text { (atestado) }\end{array}$ & $\begin{array}{c}\text { Quantidade de } \\
\text { horas extras }\end{array}$ \\
\hline Abate & 68 & 8 & $123: 13^{\prime}$ \\
\hline Bucharia & 7 & 0 & $15: 02^{\prime}$ \\
\hline Caldeiras & 5 & 0 & 09:08' \\
\hline Congelados & 18 & 4 & $49: 29^{\prime}$ \\
\hline Construção civil & 10 & 2 & $04: 25^{\prime}$ \\
\hline Controle de qualidade & 7 & $3(1)$ & $14: 24^{\prime}$ \\
\hline Cozinha & 8 & 1 & 05:44 \\
\hline Desossa & 115 & 25 & $215: 15^{\prime}$ \\
\hline Embarque & 21 & 5 & $07: 05^{\prime}$ \\
\hline Entregas & 8 & 1 & $14: 54^{\prime}$ \\
\hline Estocagem & 2 & 0 & $0: 06^{\prime}$ \\
\hline Graxaria 1 & 17 & 5 & 23:02' \\
\hline Graxaria 2 & 7 & 2 & 00:00 \\
\hline Higienização & 13 & $4(1)$ & 09:05' \\
\hline Horta & 1 & 0 & 00:00 \\
\hline Inspeção & 12 & 1 & $13: 07^{\prime}$ \\
\hline Lavanderia & 5 & 1 & 07:49' \\
\hline Limpeza externa & 11 & 1 & 19:04' \\
\hline Manutenção & 8 & 1 & $21: 05^{\prime}$ \\
\hline Miúdos & 33 & 5 & $65: 03^{\prime}$ \\
\hline Mocotó & 2 & 0 & $04: 06^{\prime}$ \\
\hline Portaria & 4 & 2 & 00:00 \\
\hline Recebimento de bois & 1 & 1 & 00:00 \\
\hline Sala de máquinas & 4 & 2 & 00:00 \\
\hline Transporte & 4 & 1 & $00: 29^{\prime}$ \\
\hline Triparia & 20 & 1 & $38: 35^{\prime}$ \\
\hline Afastados (INSS/sindicato) & 26 & & \\
\hline Total & 437 & $69(2)$ & $661: 54$ \\
\hline
\end{tabular}

Fonte: Material da pesquisa; relatório MPTOOY1.

A leitura do registro de ponto propicia algumas considerações sobre o absenteísmo. Do número total de trabalhadores (437), 95 não estavam trabalhando naquele dia. Foram 69 faltas, com apenas dois atestados, somados aos 26 afastados pelo Instituto Nacional do Seguro Social (INSS) ou para o exercício das atividades sindicais, o que representa $21,73 \%$ da força de trabalho. Outro dado importante é o número de horas extras: foram 661 horas e 54 minutos em número absoluto, o equivalente à jornada de 83 trabalhadores. 
Algumas áreas tiveram dados críticos, como o setor de abate, em que os trabalhadores, juntos, realizaram 123 horas além da jornada de trabalho, o que equivale a mais de duas horas extras, em média, para cada trabalhador, já que oito estavam ausentes. $\mathrm{O}$ setor de congelados teve uma média superior a três horas e trinta minutos extras por trabalhador. É necessário relembrar que, em ambientes artificialmente frios, como o dos congelados, não se permite a realização de horas extras. No setor de desossa, o número de trabalhadores faltantes foi 25, de um total de 115.

Infelizmente, não se teve acesso - o pedido dos dados foi negado pelo departamento jurídico da empresa - a uma série histórica do registro de ponto, para conseguir extrair tendências do prolongamento da jornada de trabalho, das ausências dos trabalhadores, do número dos afastamentos e outras informações. Contudo, referendando os fragmentos de horas extras encontrados em fontes distintas, constata-se que a extensão da jornada é algo corriqueiro no cotidiano da indústria frigorífica, mesmo que viole os dispositivos legais. Mediante os dados coletados, assume-se que o prolongamento da jornada é algo inerente ao sistema produtivo dos frigoríficos e não tem se alterado ao longo dos anos. Este foi o teor do relatório de auditoria fiscal trabalhista:

No que tange às questões firmadas no termo de conciliação parcial e que atinem ao teor da legislação trabalhista, foi contatada a reiteração de infrações relacionadas ao/à: a - não cumprimento do limite máximo de jornada; $b$ - não concessão mínima dos intervalos entre e dentro da jornada (para repouso e alimentação); c - prorrogação de labor em ambiente insalutífero; e, d - não pagamento integral das verbas salariais: não houve pagamento, e por consequência, de seus reflexos (material da pesquisa; relatório MPT00Y2).

Como expresso antes, notou-se a adoção da extensão da jornada de trabalho [mais-valor absoluto] com o aumento da produção em período habitual de trabalho [mais-valor relativo]. Como agravante dessa situação, Mato Grosso do Sul se encontra em regiões climáticas quente e subquente (IBGE, 2002), e os trabalhadores que desempenham função em ambientes com temperaturas inferiores a 15ㅇe em clima quente e 12 em clima subquente não poderiam ampliar a carga horária [fazer hora extra]. Entretanto, o que se detecta - além das figuras e do quadro, há diversos registros de infrações anotadas pelos fiscais do trabalho - é justamente o contrário. $O$ subitem a seguir discorreu sobre a inserção de maquinaria e ferramental para viabilizar a ampliação da produtividade sem sobre-esforço humano.

\section{Formas de extração de mais-valor nos frigoríficos estudados}

Com o passar dos anos, testemunhou-se que o processo da expansão do capitalismo e de suas metamorfoses tem impactado também o trabalhador (Gurgel \& Marinho, 2019). Braverman (1977, p. 124) pontua que a "transformação da humanidade trabalhadora em uma 'força de trabalho', em 'fator de produção', como instrumento do capital, [por meio de] um processo incessante e interminável", só é possível pela contínua necessidade de habituação do trabalhador. Isso se dá nas distintas tipologias de extração de mais-valor, classificadas conforme base técnica, incremento de capital constante e formas de controle (Benini, 2012). O aperfeiçoamento do controle, como denunciado por Alves (2018), além da velocidade produtiva, tem por objetivo a "captura da subjetividade" do trabalhador.

Com base no que se comentou, o frigorífico pode ser apreendido como uma manufatura moderna, que se vale da maquinaria como ferramenta auxiliar e de transporte. Inclusive os frigoríficos têm a nória e as esteiras como controladoras da velocidade da produção. Sobre a relação entre as condições de trabalho e o emprego da maquinaria, Marx sublinha:

Toda produção capitalista, por ser não apenas processo de trabalho, mas, ao mesmo tempo, processo de valorização do capital, tem em comum o fato de que não é o trabalhador quem emprega as condições de trabalho, mas, ao contrário, são estas últimas que empregam o trabalhador; porém, apenas com a maquinaria essa inversão adquire uma realidade tecnicamente tangível. Transformado num autômato, o próprio meio de trabalho se confronta, durante o processo de trabalho, com o trabalhador como capital, como trabalho morto a dominar e sugar a força de trabalho viva (Marx, 2013, p. 495).

A preocupação sobre em quais condições os trabalhadores desempenham suas atividades laborais também não é novidade: foi exteriorizada por Marx (2013) no livro I do Capital, de forma mais profunda nos capítulos 13 e 23. Druck (2011) frisa a necessidade de demonstrar as transformações e as contradições do trabalho; outros estudos mais recentes reforçam as modificações do mundo do trabalho (Almeida, Benevides \& Dutra, 2018; Ribeiro, 2019), inclusive em seu campo legal (Mello, Braga \& Sabadini, 2019). 
A identificação dos procedimentos e da maquinaria utilizada na produção levou a identificar que, durante o período desta pesquisa, não houve modificações ou incrementos, como a automação, que justificassem o aumento da produtividade. A temática de automação ou inovação tecnológica (Bernardes, Borini \& Figueiredo, 2019; Vasconcelos, Irigaray, Leal \& Carvalho, 2019) não é verificável nos frigoríficos constituintes deste artigo.

Observa-se que, de forma costumeira, se recorre à palavra "indústria" para os estabelecimentos estudados em materiais acadêmicos (Dal Magro, Coutinho \& Moré, 2016; Caleman \& Cunha, 2011). Nas fontes de pesquisa, nos procedimentos do MPT, é comum essas unidades serem nomeados de indústrias, agroindústrias ou afins. Não obstante, não se pode afirmar que o frigorífico seja uma indústria, tampouco uma indústria moderna (Cunha, 2019).

Os elementos encontrados nos frigoríficos conduzem à definição de que se trata de manufaturas modernas. Primeiramente, porque sua forma de produção é parecida com a desenvolvida no fim do século XIX, que, inclusive, inspirou Ford na implementação das linhas de montagem de seus veículos (Varussa, 2016). Braverman (1977, p. 78) assevera que o modo de produção dos frigoríficos foi a "primeira linha de montagem da indústria norte-americana, a esteira de embalagem de carne (na realidade, uma linha de desmontagem)".

Constatou-se, nos frigoríficos estudados, a utilização de capital variável como princípio operante. Apreende-se o conceito em Marx (2013, p. 286) como "a parte do capital constituída de força de trabalho [que] modifica seu valor no processo de produção. Ela não só reproduz o equivalente de seu próprio valor, como produz um excedente, um mais-valor", e tal transformação do valor se dá pela força de trabalho, ou seja, os trabalhadores.

O campo empírico explicita o uso da força de trabalho parcelar, combinado com a esteira e outras ferramentas auxiliares. Sobre a maquinaria, recorreu-se à listagem de máquinas que foram inspecionadas (material da pesquisa; relatórios do MPT). As máquinas elencadas foram divididas por setores: Abate - boxe de insensibilização, serra de chifre, serra de peito, serra de carcaça, plataforma da serra de carcaça, mesa de vísceras, guincho, guincho do primeiro pé, guincho do segundo pé, guincho da esfola do couro; Triparia - máquina de escorrer tripa, máquina de extração de mucosa, centrífuga; Miúdo/bucharia - centrífugas (todas), serra fita; Graxaria - percoladora, rosca helicoidal transportadora (rosca sem fim), moinho de martelo, rosca de abastecimento do esterilizador; Triturador - quebrador, rosca de alimentação, quebrador de cabeça. Além das máquinas por setor, foram considerados os sistemas de resfriamento, no qual se usa amônia como gás refrigerante. Nas salas de desossa, o auxílio vem das esteiras para o transporte.

A presença de máquinas que realizam o processo de forma automática se dá apenas em unidades que trabalham com o abate de aves, num processo específico, pois o maquinário atua na separação da carne que restou junto à carcaça após a desossa, que resulta no produto carne mecanicamente separada (CMS). Nos frigoríficos de bovinos, há automação quando a unidade está apta à fabricação de processados, como o hambúrguer, que é produzido por uma dessas máquinas automatizadas. Ainda assim, na unidade em que foi possível observar, o operador da máquina é responsável pela alimentação da matéria-prima, da carne e de condimentos necessários. Todavia, os referidos produtos - a CMS e os processados -, quando somados, equivaleram a pouco mais do que 4\% de toda a produção de carne no Mato Grosso do Sul em 2017 (Sipoa/DDA/SFA-MS, 2019).

Os aspectos abordados reforçam o entendimento do frigorífico como manufatura moderna, uma vez que há a participação de ferramentas auxiliares. No entanto, mantêm-se as características da manufatura. Como registrado por Cunha (2019, p. 101): "A base técnica da manufatura fica assim revelada: força de trabalho combinada e dividida segundo funções desenvolvidas pela prática e que manipula instrumentos e ferramentas de trabalho."

Soma-se a esse cenário o parcelamento das atividades em funções mínimas, como previsto por Braverman (1977), o que se evidenciou nas análises ergonômicas, expondo a função de cada posto de trabalho e a duração do ciclo das atividades aos moldes da divisão do trabalho de Smith (1988) e das descrições das funções realizada por Taylor (2012). O exemplo é o processo de trabalho dos miúdos bovinos: retirada da língua, deslocamento da mandíbula com auxílio da maquinaria, desossa da cabeça e, por fim, a limpeza das peças, como se vê na figura a seguir. 
Figura 3

Processo de trabalho na sala de miúdos, retirada da língua, deslocação da mandíbula, desossa da cabeça e limpeza das peças

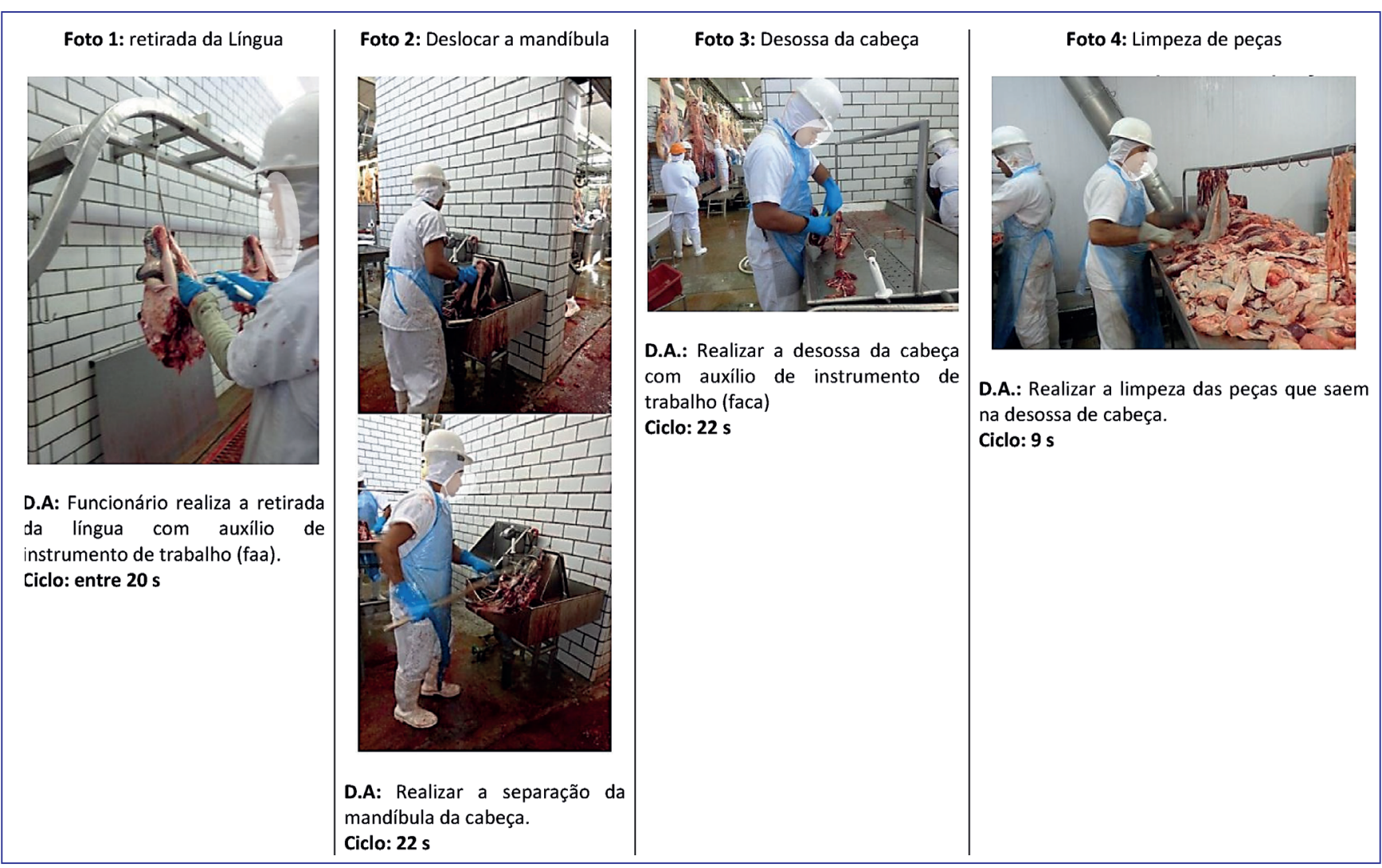

Fonte: Material da Pesquisa; relatórios do MPT00Y3.

O processo de trabalho, excluindo-se o tempo do transporte, é realizado em 75s. Uma peça inteira (cabeça bovina) é desmontada em um minuto e quinze segundos, com quatro trabalhadores designados à execução da atividade. O processo de trabalho, somado à verificação da relação de maquinaria utilizável na indústria, leva à apreensão de que os frigoríficos, como manufatura moderna, não passaram por um processo de automação ou de adoção de maquinaria para o aumento da produtividade.

\section{A INTENSIFICAÇÃO E OS AFASTAMENTOS DO TRABALHO}

Compreende-se, tal como Marx (2013, p. 483), a intensificação do trabalho como medida de "eficiência da força de trabalho". A ideia é corroborada pelo trabalho de Pina e Stotz (2014, p. 154), comentando que a intensificação "representa uma dimensão particular da exploração relativa à grandeza intensiva do trabalho e assinala a tendência à redução da porosidade da jornada".

Para mensurar a eficiência da força de trabalho, o Gráfico 1 mostra a evolução em toneladas do quantitativo de carne produzida no estado, com segmentações dos produtos. São dez subdivisões, com três de carne bovina - com osso, sem osso e outros produtos -, três de suína - idem à subdivisão de bovinos - e quatro de aves - idem aos anteriores -, mais o item CMS de aves.

Optou-se pela sistematização em toneladas produzidas, uma vez que, quando se computou a quantidade de animais abatidos, não houve alterações significativas. A discrepância é justificada pela pesquisa trimestral de abate de animais, que registrou o crescimento - em quilos - da carcaça dos bovinos (IBGE, 2019). Os dados do Ministério da Agricultura apontaram o crescimento da carcaça das aves (Sipoa/DDA/SFA-MS, 2019). O peso médio da carcaça bovina abatida em frigoríficos, segundo a Superintendência de Inspeção Federal (SIF), em janeiro de 2007, era de 232,54 quilogramas, passando a 255,27 em dezembro de 2017 , uma variação de $9,77 \%$ (IBGE, 2019). A mesma situação foi anotada por institutos de pesquisa com foco na 
bovinocultura (Universo Agro, 2018). $O$ aumento de peso também foi observado nas aves, com variação de 18,7, considerando o mesmo período: janeiro a dezembro de 2017 (Sipoa/DDA/SFA-MS, 2019). O porte do animal abatido tem efeito direto sobre o processo de trabalho, aumentando o peso das partes a serem manipuladas e, por consequência, a fadiga muscular.

A alteração do peso dos animais não é o único motivo do aumento de produção, pois o crescimento médio é menor do que a taxa de intensificação que consta na Tabela 1. Os frigoríficos se utilizam do indicador de número de cabeças abatidas na divulgação da produtividade. Todavia, na figura a seguir, decidiu-se referenciar a produtividade da indústria em toneladas, por ser a unidade de comercialização e remuneração dos frigoríficos, assim como para homogeneizar a produtividade de abate de bovinos, suínos e aves.

\section{Gráfico 1}

Produção em toneladas da indústria de abate de ovinos, suínos e aves em Mato Grosso do Sul

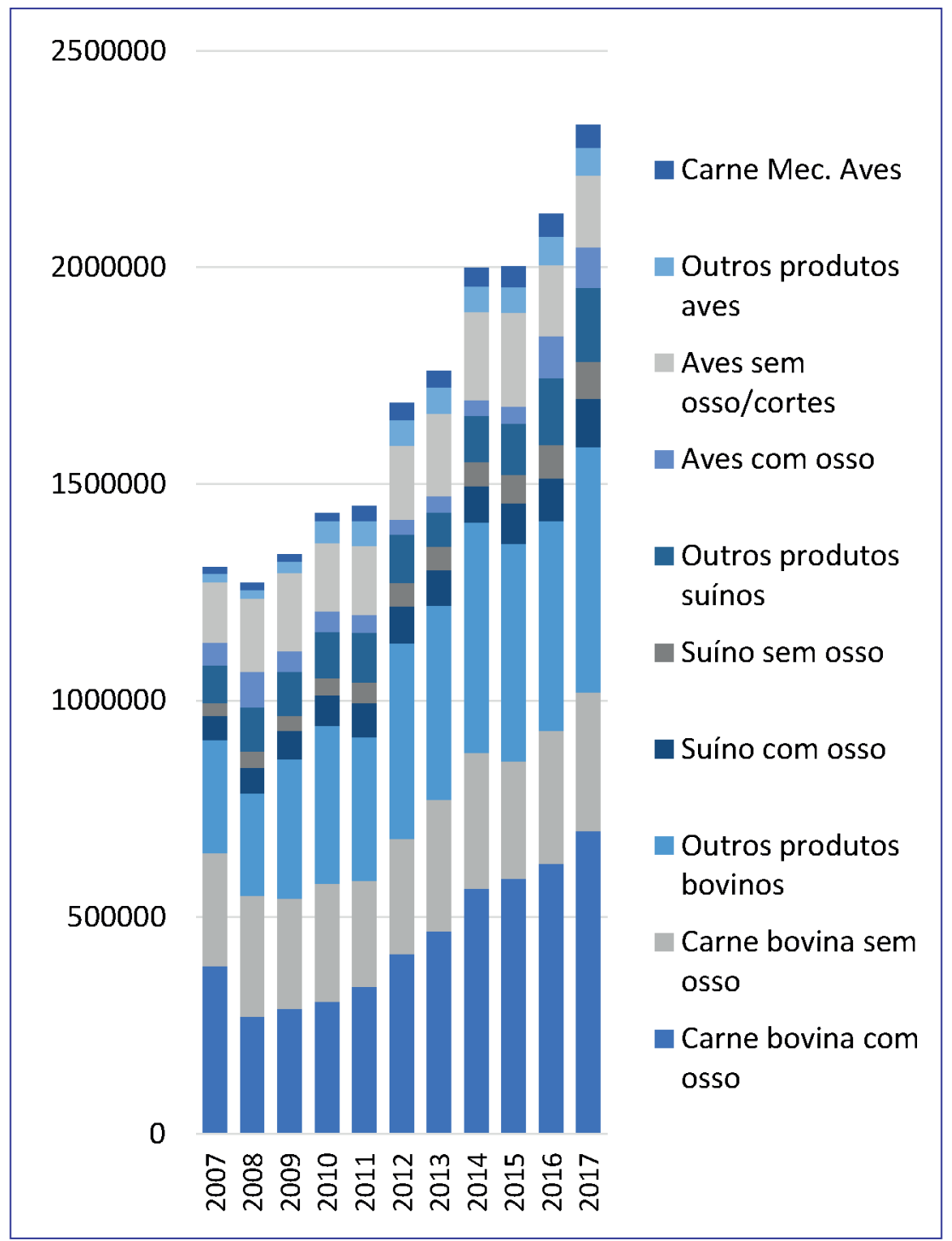

Fonte: Elaborado pelos autores (SIPOA/DDA/SFA-MS, 2019).

O Gráfico 1 evidencia um crescimento no total da produção de aproximadamente 1 milhão de toneladas de produtos, quando comparados os dados dos anos de 2007 e 2017. Foram 1,30 milhão de toneladas em 2007 de carne; em 2017, esse número ultrapassou 2,32 milhões de toneladas produzidas. Não obstante, o crescimento de $77,9 \%$ na produção de carne no estado foi discrepante e não proporcional ao aumento no número de trabalhadores empregados no setor. Como se vê no Quadro 2, o número de empregados no setor teve um crescimento de apenas $15 \%$. 
Salienta-se o incremento produtivo obtido nos frigoríficos pelo uso e pela adequação da força de trabalho. Inclusive, o crescimento da produção se deu num período histórico, quando foram inseridas as pausas de recuperação térmicas pela NR-36, ${ }^{4}$ e ainda assim houve o aumento da produção. A inserção das pausas e o crescimento produtivo remetem à experiência de Elton Mayo, realizada em Hawthorne, na cidade de Chicago.

Não há uma única forma de jornada de trabalho. Alguns frigoríficos dividem a jornada em seis dias, com oito horas de segunda a sexta-feira e quatro aos sábados. Outros adaptaram a jornada para cinco dias, com expedientes de segunda a sexta, com jornada de oito horas e quarenta e oito minutos. Há outras possibilidades, mas a forma amplamente encontrada é de jornada com cinco dias. Nesse formato, são distribuídas três pausas durante a rotina do trabalho. A introdução das pausas proporcionou ao trabalhador uma redução da carga horária de 44 horas semanais para aproximadamente 39 , o equivalente a 11,36\% da jornada semanal. A distribuição das pausas e os horários de expediente utilizados pelos frigoríficos seguem, em geral, a rotina constante do quadro a seguir.

\section{Quadro 2}

\section{Jornada de trabalho comumente empregada nos frigoríficos}

\begin{tabular}{|c|c|}
\hline Atividade & Horário \\
\hline Início da jornada & $6 \mathrm{~h}$ \\
\hline Primeira pausa & $7 \mathrm{~h} 40$ \\
\hline Retorno & $8 \mathrm{~h}$ \\
\hline Segunda pausa & $9 \mathrm{~h} 40$ \\
\hline Retorno & $10 \mathrm{~h}$ \\
\hline Intervalo almoço & $11 \mathrm{~h} 30$ \\
\hline Retorno almoço & $12 \mathrm{~h} 30$ \\
\hline Terceira pausa & $14 \mathrm{~h} 10$ \\
\hline Retorno & $14 \mathrm{~h} 30$ \\
\hline Término da jornada & $15 \mathrm{~h} 48$ \\
\hline
\end{tabular}

Fonte: Material da Pesquisa; relatório MPTO0Y2; MPTO0Y3; processos TRT00X1; TRT00X2.

Com base no comentário sobre o aumento da produção e pelo fato de isso ter ocorrido pela intensificação do trabalho, na Tabela 1 se verifica a taxa de intensificação. A partir de 2014, aparece o número de trabalhadores ajustados, que é o número de trabalhadores, diminuindo-se a redução da carga horária (os 11,36\% antes citados). Assim, tem-se o número de trabalhadores proporcionais, caso fosse mantida a mesma carga horária. Quando se divide a produção pelo número de trabalhadores ajustados, obtém-se a produção proporcional. A última coluna informa a taxa de intensificação.

${ }^{4}$ A NR-36 normatiza o trabalho nos frigoríficos, estipulando intervalos intrajornada, nomeados como pausa de recuperação psicofisiológica (Ministério do Trabalho e Emprego [MTE], 2013). 
Tabela 1

Produtividade por trabalhador ajustado e taxa de intensificação do trabalho

\begin{tabular}{|c|c|c|c|c|c|c|c|}
\hline Ano & $\begin{array}{l}\text { Produção } \\
\text { (ton.) }\end{array}$ & Trabalhador & $\begin{array}{c}\text { Trabalhador } \\
\text { Ajustado }\end{array}$ & $\begin{array}{l}\text { Produção } \\
\text { per capita }\end{array}$ & $\begin{array}{c}\text { Produção } \\
\text { proporcional }\end{array}$ & $\begin{array}{c}\text { Taxa de } \\
\text { intensificação } \\
\text { per capita }\end{array}$ & $\begin{array}{c}\text { Taxa de } \\
\text { intensificação } \\
\text { ajustada }\end{array}$ \\
\hline & [a] & [b] & {$[c]=b-11,36 \%$} & {$[d]=a / b$} & {$[e]=a / c$} & {$[\mathrm{~h}]$} & [i] \\
\hline 2007 & 1308637 & 22713 & 22713 & 57,62 & 57,62 & 1,00 & 1,00 \\
\hline 2008 & 1272592 & 22235 & 22235 & 57,23 & 57,23 & 0,99 & 0,99 \\
\hline 2009 & 1337777 & 22199 & 22199 & 60,26 & 60,26 & 1,05 & 1,05 \\
\hline 2010 & 1433510 & 20180 & 20180 & 71,04 & 71,04 & 1,23 & 1,23 \\
\hline 2011 & 1449825 & 21565 & 21565 & 67,23 & 67,23 & 1,17 & 1,17 \\
\hline 2012 & 1686920 & 24620 & 24620 & 68,52 & 68,52 & 1,19 & 1,19 \\
\hline 2013 & 1760938 & 24092 & 24092 & 73,09 & 73,09 & 1,27 & 1,27 \\
\hline 2014 & 1998948 & 24440 & 21662,74 & 81,79 & 92,28 & 1,42 & 1,60 \\
\hline 2015 & 2002717 & 24058 & 21324,15 & 83,25 & 93,92 & 1,44 & 1,63 \\
\hline 2016 & 2124351 & 23353 & 20699,26 & 90,97 & 102,63 & 1,58 & 1,78 \\
\hline 2017 & 2329304 & 26135 & 23165,12 & 89,13 & 100,55 & 1,55 & 1,75 \\
\hline
\end{tabular}

Fonte: Elaborada pelos autores (MTE, s.d.; Sipoa/DDA/SFA-MS, 2019).

Como opção pela exposição da taxa de intensificação, tem-se por base o ano de 2007. A produção e os fatores de intensificação estão presentes no trabalho frigorífico desde as primeiras formas de divisão do trabalho. No entanto, tendo em vista os afastamentos de longos períodos, assume-se que o ano de 2007 é fundamental para a compreensão da intensificação. Assim, os anos seguintes foram calculados com base na produção alcançada nesse ano. Constata-se que a adição das pausas não reduziu a produtividade, em números absolutos ou proporcionais, como visto nas colunas [d] e [e] da Tabela 1. A inserção da pausa, pela NR-36 (MTE, 2013), teve como efeito a elevação da produtividade individual e, por consequência, da taxa de intensificação.

Muitos trabalhadores, responsáveis pelo aumento da eficiência produtiva, recebem como sequela o adoecimento (Dario \& Lourenço, 2018; Santos \& Oliveira, 2018). Como os números por vezes mascaram os dados de adoecimento (Fundação Sistema Estadual de Análise de Dados \& Fundação Jorge Duprat Figueiredo de Segurança e Medicina do Trabalho, 2012; Krein, 2018), recorreu-se aos dados de afastamentos constantes na RAIS. Configuraram-se afastamentos de longo período os casos com 360 dias ou mais durante o ano referência. 
Gráfico 2

Afastamentos de longo período das empresas de abate e processamento de carnes no estado de Mato Grosso do Sul

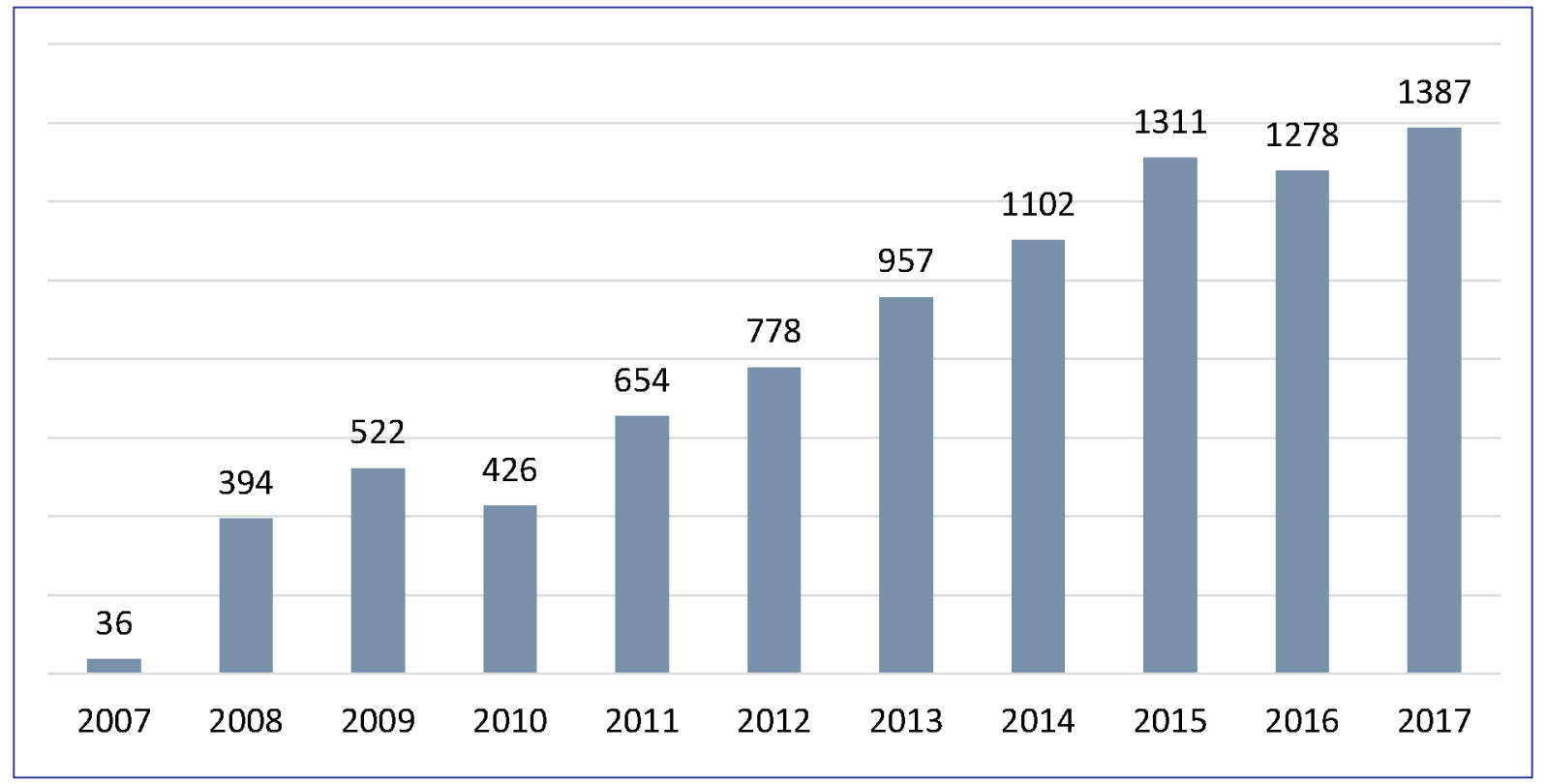

Fonte: Elaborado pelos autores (MTE, s.d.).

O gráfico inclui, como afastamentos de longos períodos, aqueles com registro de 360 dias ou mais no mesmo ano. Esses dados estão disponíveis na RAIS, motivo pelo qual pode ter havido um acúmulo dos anos. Por exemplo, em 2017, em que consta o número 1387, não se informa quando se deu o início do afastamento desses trabalhadores; apenas a quantidade de trabalhadores que estavam afastados das atividades laborativas por 360 dias ou mais. Ainda assim, mesmo com as lacunas, computa-se que, de 2008 a 2017, foi triplicado o número de trabalhadores afastados.

"O tempo de afastamento do trabalho tem sido apontado como um considerável fator relacionado ao retorno ao trabalho. Um menor tempo de duração foi encontrado como um facilitador do processo" (Saldanha, Pereira, Neves \& Lima, 2013). No caso do recorte estudado em Mato Grosso do Sul, tem-se visto um alargamento no número de afastamentos de longos períodos. Isso é corroborado pela análise quantitativa de regressão linear, com a variável dependente, os afastamentos em t [ano] e a variável independente de produção, valores da coluna [a] da Tabela 1, ajustada em t-1. 0 decréscimo da variável independente no tempo foi necessária para buscar equivalência explicativa no modelo (Figueiredo \& Silva, 2018). O volume de produção do ano t-1 explica o número de afastamento em t. O valor mensurado da correlação de Pearson é 0,980. Assim, constata-se a correlação positiva entre as variáveis. Foi gerada uma equação do modelo explicativo [com fator $R^{2}$ de $96,1 \%$ ]. Entretanto, a relevância dessa técnica para o estudo é apenas corroborar os dados qualitativos identificados. Embora se admita a limitação do tamanho da amostra, os pressupostos de homocedasticidade e correlação parcial [autocorrelação] foram preservados (Hair, Black, Babin, Anderson \& Tatham, 2009). 


\section{CONCLUSÃO}

O aumento destoante entre a produção e a força de trabalho é visível em algumas situações, nas quais se destacam a ampliação da maquinaria e a intensificação do trabalho. Como argumentado, o frigorífico pode ser conceituado como uma manufatura moderna. Não se tem registro, no tempo histórico desta pesquisa, da automação dos processos de trabalho relativos ao abate e à desossa, exceto os casos já citados, da CMS e da produção de hambúrgueres. Acrescenta-se que a automação ou a adoção de maquinaria automática para esses produtos remete aos anos 2000 , antes do período desta análise. Observou-se o emprego de ferramentas automáticas de transporte, como a eletrização da nória, em alguns casos. Contudo, não há elementos que comprovem a automatização da produção ou o crescimento vertiginoso da produtividade pelo emprego de maquinaria. Assim, o incremento da produção tem-se dado pelos instrumentos de divisão e controle do trabalho.

Os dados da Tabela 1 demonstram o agravamento da exploração do trabalho, quando se mensuram o número de trabalhadores do setor e o total da produção. Em 2017, o trabalhador produziu 75\% a mais do que em 2007. No período de 2007 a 2017, com a inserção das pausas de recuperação térmica, os trabalhadores tiveram uma redução de $11,36 \%$ no tempo de trabalho. Foram introduzidas três pausas de vinte minutos cada. Assim, o trabalhador que estava disponível na empresa por oito horas e quarenta e oito minutos, após 2013 produziu durante sete horas e quarenta e oito minutos. A redução do tempo não influenciou na produção; ao contrário, ampliou-a, reduzindo o tempo necessário da força de trabalho. Em números absolutos e relativos, a pausa psicofisiológica incluída na NR-36 fez crescer a produção e a intensificação do trabalho.

Como anunciado no início do texto, este artigo explicita a demanda dos trabalhadores na área dos estudos organizacionais. Demonstraram-se, com dados e informações materiais, o avanço da intensificação do trabalho e seus efeitos sobre os trabalhadores envolvidos no processo produtivo. Debruçou-se sobre as métricas de quantificação, a fim de clarificar os elementos probantes de um processo de intensificação e controle do trabalho, circunscritos em processos manufatureiros de produção que mostram o exacerbado crescimento dos afastamentos de trabalhadores, o que pode ser classificado como uma patologia organizacional. Conforme se atestou, é preciso inserir o frigorífico como expressão organizacional particularmente atrasada no desenvolvimento técnico-produtivo, revelando-se formas pré-industriais de controle e incremento produtivos, mais ligadas ao esforço físico, portanto, como um local capaz de acarretar adoecimento ao trabalhador.

A ampliação do mais-valor produzido está conexa e se estende a fatores externos à fábrica - houve, no período estudado, aumento no peso da carcaça do bovino abatido. 0 crescimento no tamanho da peça faz com que o trabalhador tenha de dedicar mais força para puxar e empurrar. Também há mais carne para refilar, o que requer mais esforço para a execução do trabalho. Esse fator amplifica o processo de intensificação do trabalho, que pode ocasionar, como principal consequência, o adoecimento dos trabalhadores.

A intensificação ocorrida no período levou ao aumento do número de afastamentos de longo período entre 2007 e 2017 (MTE, s.d.). Houve uma massa de trabalhadores afastados por longos períodos. Foram 1387 trabalhadores afastados de suas atividades laborais durante o ano de 2017, por 360 dias ou mais. Esse número representa 5,3\% dos trabalhadores do setor. No início do período, em 2007, os registros apontaram apenas 36 afastamentos de longo período. Optou-se, neste texto, por considerar o tempo de afastamento, sem o levantamento dos afastamentos por motivos laborais.

Não se segmentaram as anotações entre motivos laborais e não laborais. Houve informações de pessoas adoecidas graças ao mesmo Código Internacional de Doenças (CID), desempenhando a mesma função, com dados de afastamentos que identificaram o adoecimento como algo externo ao frigorífico, registrados com o código B31, no INSS. Essa limitação do estudo remete à viabilidade de pesquisas futuras, junto com a mensuração do total dos afastamentos, acompanhada da identificação das suas causas. 


\section{REFERÊNCIAS}

Aktouf, O. (2004). Pós-globalização, administração e racionalidade econômica: a Síndrome do Avestruz. São Paulo, SP: Atlas.

Almeida, L. T. D. C., Benevides, T. M., \& Dutra, R. Q. (2018). Gestão e precarização do trabalho: Uma Análise da influência da Atuação Gestora na Vida dos Trabalhadores de Call Centers. Revista Ibérica de Sistemas e Tecnologias de Informação, 28, 72-85.

Alves, G. (2018). O duplo negativo do capital: ensaio sobre a crise do capitalismo global. Bauru, SP: Canal 6.

Antunes, R. (2011, setembro). Os modos de ser da informalidade: rumo a uma nova era da precarização estrutural do trabalho? Serviço Social \& Sociedade, 107, 405-419, 2011.

Benini, E. G. (2012). Política educacional e educação a distância: as contradições engendradas no âmbito do trabalho docente (Tese de Doutorado). Universidade Federal de Mato Grosso do Sul, Campo Grande, MT.

Bernardes, R., Borini, F., \& Figueiredo, P. N. (2019). Inovação em Organizações de Economias Emergentes. Cadernos EBAPE.BR, 17(4), 886-894.

Braverman, H. (1977). Trabalho e capital monopolista: a degradação do trabalho no século XX. Rio de Janeiro, RJ: J. Zahar, 1977.

Caleman, S. M. D. Q., \& Cunha, C. F. (2011). Estrutura e conduta da agroindústria exportadora de carne bovina no Brasil. Organizações Rurais \& Agroindustriais, 13(1), 93-108.

Cunha, E. (2019). Base técnica e organização do trabalho na manufatura e grande indústria: inflexão, desenvolvimento desigual e reciprocidade. Verinotio - Revista on-line de Filosofia e Ciências Humanas, 25(1), 88-128.

Cunha, E., \& Ferraz, D. L. S. (2015). Marxismo, Estudos Organizacionais e a luta contra o irracionalismo. Organização e Sociededade, 22(73), 193-198.

Dal Magro, M. L. P., Coutinho, M. C., \& Moré, C. L. O. O. (2016). Relações de poder na atenção à saúde do trabalhador formal: o caso da indústria de abate e processamento de carnes. Revista Brasileira de Saúde Ocupacional, 41, e4.

Dario, V. C., \& Lourenço, M. L. (2018). Cultura Organizacional e Vivências de Prazer e Sofrimento no Trabalho: Um Estudo com Professores de Instituições Federais de Ensino Superior. Revista Organizações em Contexto, 14(27), 345-395.

Davel, E., \& Alcadipani, R. (2003). Estudos críticos em administração: a produção científica brasileira no anos 1990. Revista de Administração de Empresas, 43(4), 72-85.

Druck, G. (2011). Trabalho, precarização e resistências: novos e velhos desafios? Caderno $C R H, 24$ (spe1), 37-57.

Faria, J. H. (2009). Teoria crítica em estudos organizacionais no Brasil: o estado da arte. Cadernos EBAPE.BR, 7(3), 509-515.

Faria, J. H., \& Meneghetti, F. K. (2010). (Sem) saber e (com) poder nos estudos organizacionais. Cadernos EBAPE.BR, 8(1), 38-52.
Figueiredo, C. D. C., \& Silva, A. F. D. (2018). Aplicação da Modelagem de Regressão em Dados Observados ao Longo do Tempo. Internext, 13(3), 42-50.

Fundação Sistema Estadual de Análise de Dados, \& Fundação Jorge Duprat Figueiredo de Segurança e Medicina do Trabalho. (2012). Vinculação de bancos de dados de acidentes do trabalho fatais dos Estados de São Paulo e Minas Gerais 2006-2008. São Paulo, SP: Autor.

Gurgel, C., \& Marinho, M. (2019). Escravidão contemporânea e oyotismo. Organizações \& Sociedade, 26(89), 317-337.

Hair, J. F., Black, W. C., Babin, B. J., Anderson, R. E., \& Tatham, R. L. (2009). Análise Multivariada de Dados (6. ed.). Porto Alegre, RS: Bookman.

Instituto Brasileiro de Geografia e Estatística. (2002). Mapa de Clima do Brasil. Rio de Janeiro, RJ: Autor.

Instituto Brasileiro de Geografia e Estatística. (2019). Pesquisa Trimestral de Abate de Animais. Brasília, DF: Autor. Recuperado de https:// www.ibge.gov.br/estatisticas-novoportal/economicas/agriculturae-pecuaria/21119-primeiros-resultados-2abate.html?=\&t=resultados

Ju, D., Qin, X., Xu, M. Y., \& Direnzo, M. S. (2016). Boundary conditions of the emotional exhaustion-unsafe behavior link: The dark side of group norms and personal control. Asia Pacific Journal of Management, 33(1), 113-140.

Krein, J. D. (2018). O desmonte dos direitos, as novas configurações do trabalho e o esvaziamento da ação coletiva: consequências da reforma trabalhista. Tempo Social, 30(1), 77-104.

Lacaz, F. A. D. C. (2016). Continuam a adoecer e morrer os trabalhadores: as relações, entraves e desafios para o campo Saúde do Trabalhador. Revista Brasileira de Saúde Ocupacional, 41, e13.

Lukács, G. (2013). Para uma ontologia do ser social I. São Paulo, SP: Boitempo.

Marx, K. (2013). O Capital: Crítica da economia política: O processo de produção do capital. São Paulo, SP: Boitempo.

Mello, G., Braga, H., \& Sabadini, M. D. S. (2019). Capital accumulation, crisis, and labor market in modern Brazil. Revista Katálysis, 22(1), 15-35.

Ministério da Agricultura. (2018). Sistema de Informação do Sistema de Inspeção Federal. Recuperado de http://sigsif.agricultura.gov.br Ministério do Trabalho e Emprego. (s.d.). Relação Anual de Informações Sociais. Brasília, DF: Autor.

Ministério do Trabalho e Emprego. (2013). NR 36: Segurança e saúde do trabalhador em empresas de abate e processamento de carnes e derivados. Brasília, DF: Diário Oficial da União.

Paula, A. P. P. (2008). Teoria Crítica nas Organizações. São Paulo, SP: Thomson Learnin.

Pina, J. A., \& Stotz, E. N. (2014). Intensificação do trabalho e saúde do trabalhador: uma abordagem teórica. Revista Brasileira de Saúde Ocupacional, 39(130), 150-160. 
Ribeiro, R. F. (2019). A unidade financeirização e autorreprodução do capital: pressupostos marxianos e elementos contemporâneos. Revista Katálysis, 22(1), 171-180.

Romero, D. (2005). Marx e a técnica: um estudo dos manuscritos de 1861-1863. São Paulo, SP: Expressão Popular.

Saldanha, J. H. S., Pereira, A. P. M., Neves, R. D. F., \& Lima, M. A. G. D. (2013). Facilitadores e barreiras de retorno ao trabalho de trabalhadores acometidos por LER/DORT. Revista Brasileira de Saúde Ocupacional, 38(127), 122-138.

Santos, S. R. T. G. D., \& Oliveira, L. H. D. (2018). Afastamento do Trabalho: Análise da Percepção de Gestores e Reabilitados Reintegrados à Empresa de Maneira Sustentável. Perspectivas em Gestão \& Conhecimento, 8(3), 40-66.

Serviço de Inspeção de Produtos de Origem Animal. (2019). SIPOA/ DDA/SFA-MS. Dados de pesquisa. Mato Grosso do Sul, MT: Minitério da Agricultura.

Smith, A. (1988). A riqueza das nações (Os Economistas). São Paulo, SP: Nova Cultural.

Taylor, F. W. (2012). Princípios de administração científica (8. ed.). São Paulo, SP: Atlas.
Universo Agro. (2018). Sistema do Boi 7.7.7 gera lucro na pecuária. Recuperado de http://www.esalq.usp.br/cprural/noticias/mostra/6267/ sistema-do-boi-777-gera-lucro-na-pecuaria.html

Varussa, R. J. (2016). Eu trabalhava com dor: trabalho e adoecimento nos frigoríficos. Jundiaí, SP: Paco Editorial.

Vasconcelos, I. F. F. G., Irigaray, H. A. R., Leal, F. B., \& Carvalho, L. A. (2019). Inovação tecnológica radical e mudança organizacional: a institucionalização de organizações resilientes e formas de trabalho mais substantivas. Cadernos EBAPE.BR, 17(4), 895-922.

Vasconcellos, M. D. C., Pignatti, M. G., \& Pignati, W. A. (2009). Emprego e acidentes de trabalho na indústria frigorífica em áreas de expansão do agronegócio, Mato Grosso, Brasil. Saúde e Sociedade, $18,662-672$.

Vilela, R. A. G., Jackson, J. M., Filho, Querol, M. A. P., Gemma, S. F. B., Takahashi, M. A. C., Gomes, M. H. P., ... Almeida, I. M. (2018). A expansão do objeto da vigilância em acidente do trabalho: história e desafios de um centro de referência em busca da prevenção. Ciência \& Saúde Coletiva, 23(9), 3055-3066.

Zylberstajn, D. (2013). Administração de sistemas de base agrícola: análise de fatores críticos. Revista de Administração, 48(2),203-207.

Gustavo Henrique Petean

ORCID: https://orcid.org/0000-0003-1248-6418

Doutor em Administração; Professor da Universidade Federal de Goiás (UFG). E-mail: gustah@gmail.com

Elcio Gustavo Benini

ORCID: https://orcid.org/0000-0002-0949-3062

Doutor em Educação; Professor da Universidade Federal de Mato Grosso do Sul (UFMS). E-mail: elciobenini@yahoo.com.br 